\title{
Common fixed point theorems for Ćirić type mappings in b-metric spaces without any completeness assumption
}

\author{
Borimandafu Wu, Fei He*, Tao Xu \\ School of Mathematical Sciences, Inner Mongolia University, Hohhot 010021, China.
}

Communicated by F. Vetro

\begin{abstract}
In this paper, we establish some common fixed point theorems for four mappings satisfying Ćirić type contractive condition in b-metric spaces without any completeness assumption. Our results improve and generalize the results in the very recent papers ([Z.-Z. Yang, H. Sadati, S. Sedghi, N. Shobe, J. Nonlinear Sci. Appl., 8 (2015), 1022-1031], [V. Ozturk, S. Radenović, SpringerPlus, 5 (2016), 10 pages]). Particularly, the contractive constant $\frac{k}{b^{2}}$ in the result of Yang et al. is enlarged to $\frac{k}{b}$. Some examples are provided to support our results. (C)2017 All rights reserved.
\end{abstract}

Keywords: Common fixed point, Ćirić type contractive mapping, (CLRS)-property, b-metric space.

2010 MSC: $47 \mathrm{H} 10,54 \mathrm{H} 25$.

\section{Introduction and preliminaries}

The Banach contraction principle is a basic and remarkable result in fixed point theory. Over the years, it has been extended in many different directions and spaces, see [4, 5, 8, 9, 11-14, 17, 21, 23, 24] and the references therein. In 1974, Ćirić [9] introduced the concept of a quasi-contractive mapping, i.e., a self-mapping $\mathrm{T}: \mathrm{X} \rightarrow \mathrm{X}$ satisfies

$$
d(T x, T y) \leqslant k \max \{d(x, y), d(x, T x), d(y, T y), d(x, T y), d(y, T x)\}
$$

for all $x, y \in X$ and for a constant $k \in[0,1)$, and proved a quasi-contractive mapping must have a unique fixed point in a complete metric space. Recently, Yang [23] obtained a common fixed point theorems for non-compatible self-maps in G-metric spaces. Roldán-López-de-Hierro et al. [21] noticed that the (CLRS)-property is weaker than the non-compatibleness, and improved the results of Yang [23]. On the other hand, Aamri and Moutawakil [1] introduced the (E.A)-property which is also weaker than the non-compatibleness. Using this concept, many authors established some new fixed point results, see, for example, [2, 6, 18-20]. In particular, Ozturk and Radenović [19] established some common fixed point results for four self-mappings in b-metric spaces which improved and generalized the results of

\footnotetext{
*Corresponding author

Email address: hefei@imu.edu.cn (Fei He)
} 
Ozturk and Turkoglu [20]. Very recently, Yang et al. [24] proved a new common fixed point theorem for non-compatible self-mappings in b-metric space, where the space is not necessarily complete.

Inspired by the ideas of Yang et al. [24], Roldán-López-de-Hierro et al. [21], and Ozturk et al. [19], by using the notion of (CLRS)-property, we establish some common fixed point theorems for quasicontractive mappings of Ćirić type in b-metric spaces. Our results improve the results of Yang et al. [24] and Ozturk et al. [19]. Particularly, the contractive constant $\frac{\mathrm{k}}{\mathrm{b}^{2}}$ in the result of Yang et al. [24] is enlarged to $\frac{k}{b}$. We notice that a gap arises in the proof of the main result of Yang et al. [24]; also refer to [21, Remark 11]. In this work, we also fill this gap; see Remark 2.5.

Let us recall some basic notions and results about b-metric spaces; see, for instance, [7, 10, 24].

Definition 1.1. Let $X$ be a nonempty set and $b \geqslant 1$ be a given real number. A function $d: X \times X \rightarrow[0, \infty)$ is called a b-metric on $X$ if the following conditions hold:

(b1) $d(x, y)=0$ if and only if $x=y$;

(b2) $d(x, y)=d(y, x)$ for any $x, y \in X$;

(b3) $d(x, y) \leqslant b(d(x, z)+d(z, y))$ for any $x, y, z \in X$.

Then the pair $(X, d)$ is called a b-metric space (or metric type space).

Definition 1.2. Let $(X, d)$ be a b-metric space.

(1) The sequence $\left\{x_{n}\right\}$ converges to $x \in X$ if and only if $\lim _{n \rightarrow \infty} d\left(x_{n}, x\right)=0$;

(2) the sequence $\left\{x_{n}\right\}$ is Cauchy if and only if $\lim _{n, m \rightarrow \infty} d\left(x_{n}, x_{m}\right)=0$;

(3) the space $(X, d)$ is complete if and only if every Cauchy sequence in $X$ is convergent.

Remark 1.3. In a $\mathrm{b}$-metric space $(\mathrm{X}, \mathrm{d})$ the following assertions hold:

(i) a convergent sequence has a unique limit;

(ii) each convergent sequence is Cauchy;

(iii) in general, a b-metric is not continuous.

In the sequel, let $(X, d)$ be a $b$-metric space and let $f, S: X \rightarrow X$ be two self-mappings. The following notions and basic results can be found, for instance, in $[15,21,24]$.

Definition 1.4. The pair $(f, S)$ is said to be compatible if

$$
\lim _{n \rightarrow \infty} d\left(f S x_{n}, S f x_{n}\right)=0,
$$

whenever $\left\{x_{n}\right\}$ is a sequence in $X$ such that $\lim _{n \rightarrow \infty} f x_{n}=\lim _{n \rightarrow \infty} S x_{n}=z$ for some $z \in X$.

Definition 1.5. The self-mappings $f$ and $S$ of $X$ are said to be

(a) R-weakly commuting mappings of type $\left(A_{f}\right)$ if there exists a positive real number $R$ such that $d(f S x, S S x) \leqslant R d(f x, S x)$ for all $x \in X$.

(b) R-weakly commuting mappings of type $\left(A_{S}\right)$ if there exists a positive real number $R$ such that $d(S f x, f f x) \leqslant R d(S x, f x)$ for all $x \in X$.

Definition 1.6. The pair $(f, S)$ is said to be weakly compatible if $f$ and $S$ commute at their coincidence points, that is $f S x=S f x$ whenever $f x=S x$.

Remark 1.7. It is clear to see that if $f$ and $S$ are R-weakly commuting mappings of type $\left(A_{f}\right)$ or R-weakly commuting mappings of type $\left(A_{S}\right)$ then the pair $(f, S)$ is weakly compatible.

Definition 1.8. The self-mapping $f$ of $a b$-metric space $(X, d)$ is said to be $b$-continuous at $x \in X$ if and only if it is $b$-sequentially continuous at $x$, that is, $\left\{f\left(x_{n}\right)\right\}$ is convergent to $f(x)$ whenever $\left\{x_{n}\right\}$ is convergent to $x$. 
Yang et al. [24] gave the following result.

Theorem 1.9 ([24]). Let $(\mathrm{X}, \mathrm{d})$ be a b-metric space and $(\mathrm{f}, \mathrm{S})$ be a pair of non-compatible self-mappings with $\overline{\mathrm{fX}} \subseteq \mathrm{SX}$ (here $\overline{\mathrm{fX}}$ denotes the closure of $\mathrm{fX}$ ). Assume the following conditions are satisfied

$$
d(f x, f y) \leqslant \frac{k}{b^{2}} \max \{d(S x, S y), d(f x, S x), d(f y, S y)\}
$$

for all $x, y \in X$ and $0<k<1$. If $(f, S)$ is a pair of $R$-weakly commuting mappings of type $\left(A_{S}\right)$, then $f$ and $S$ have a unique common fixed point (say $z$ ) and both $\mathrm{f}$ and $\mathrm{S}$ are not $\mathrm{b}$-continuous at $\mathrm{z}$.

Definition $1.10([19,20])$. The self-mappings $f$ and $S$ on $X$ are said to satisfy the b-(E.A) property if there exists a sequence $\left\{x_{n}\right\}$ such that $\lim _{n \rightarrow \infty} f x_{n}=\lim _{n \rightarrow \infty} S x_{n}=t$ for some $t \in X$.

We carry the notion of the (CLRS)-property to b-metric spaces; refer to [3, 21, 22].

Definition 1.11. Let $f, S, T: X \rightarrow X$ be three self-mappings of a b-metric space $(X, d)$. We say that the pair $(f, S)$ satisfies the common limit in the range of T property (briefly, (CLRT)-property) if there exists a sequence $\left\{x_{n}\right\} \subseteq X$ and a point $u \in X$ such that

$$
\lim _{n \rightarrow \infty} f x_{n}=\lim _{n \rightarrow \infty} S x_{n}=T u \in T X .
$$

Particularly, if $T=S$, we say that the pair $(f, S)$ satisfies the (CLRS)-property if there exists a sequence $\left\{x_{n}\right\} \subseteq X$ and a point $u \in X$ such that

$$
\lim _{n \rightarrow \infty} f x_{n}=\lim _{n \rightarrow \infty} S x_{n}=S u \in S X
$$

Lemma 1.12 ([19]). If $(\mathrm{f}, \mathrm{S})$ is not compatible, then ( $\mathrm{f}, \mathrm{S})$ satisfies the b-(E.A) property.

Lemma 1.13. If $(f, S)$ satisfies the $b-(E . A)$ property and $\overline{f X} \subseteq T X$, then $(f, S)$ satisfies the (CLRT)-property.

\section{Main results}

The following are main results of this paper.

Theorem 2.1. Let $(\mathrm{X}, \mathrm{d})$ be $a \mathrm{~b}$-metric space with $\mathrm{b} \geqslant 1$ and $\mathrm{f}, \mathrm{g}, \mathrm{S}, \mathrm{T}: \mathrm{X} \rightarrow \mathrm{X}$ four self-mappings. Suppose that there exists $k \in[0,1)$ such that

$$
d(f x, g y) \leqslant \frac{k}{b} \max \{d(S x, T y), d(f x, S x), d(g y, T y), d(f x, T y), d(S x, g y)\}
$$

for all $x, y \in X$. If $(f, S)$ satisfies the (CLRT)-property and $(\mathrm{g}, \mathrm{T})$ satisfies the (CLRS)-property, then ( $\mathrm{f}, \mathrm{S})$ and $(\mathrm{g}, \mathrm{T})$ have a point of coincidence in X. Moreover, if the pairs $(\mathrm{f}, \mathrm{S})$ and $(\mathrm{g}, \mathrm{T})$ are weakly compatible, then $\mathrm{f}, \mathrm{g}, \mathrm{S}$, and $\mathrm{T}$ have a unique common fixed point.

Proof. As $(f, S)$ satisfies the (CLRT)-property and $(g, T)$ satisfies the (CLRS)-property, there exist sequences $\left\{x_{n}\right\}$ and $\left\{y_{n}\right\}$ in $X$ and $u, v \in X$ such that

$$
\begin{aligned}
& \lim _{n \rightarrow \infty} f x_{n}=\lim _{n \rightarrow \infty} S x_{n}=T u \in T X, \\
& \lim _{n \rightarrow \infty} g y_{n}=\lim _{n \rightarrow \infty} T y_{n}=S v \in S X .
\end{aligned}
$$

The proof is broken into the following three steps.

Step 1. We prove that $g u=T u$, that is $(g, T)$ has a point of coincidence in $X$. From (2.1), we see that

$$
d\left(f x_{n}, g u\right) \leqslant \frac{k}{b} \max \left\{d\left(S x_{n}, T u\right), d\left(f x_{n}, S x_{n}\right), d(g u, T u), d\left(f x_{n}, T u\right), d\left(S x_{n}, g u\right)\right\} .
$$

Notice the following two facts. 
(i) $d\left(f x_{n}, g u\right) \leqslant \frac{k}{b} d(g u, T u) \leqslant k d\left(g u, f x_{n}\right)+k d\left(f x_{n}, T u\right)$ implies $d\left(f x_{n}, g u\right) \leqslant \frac{k}{1-k} d\left(f x_{n}, T u\right)$.

(ii) $d\left(f x_{n}, g u\right) \leqslant \frac{k}{b} d\left(S x_{n}, g u\right) \leqslant k d\left(S x_{n}, f x_{n}\right)+k d\left(f x_{n}, g u\right)$ implies $d\left(f x_{n}, g u\right) \leqslant \frac{k}{1-k} d\left(S x_{n}, f x_{n}\right)$.

Thus, using (2.4) and $\frac{k}{b}<\frac{k}{1-k}$, we deduce that

$$
\begin{aligned}
d\left(f x_{n}, g u\right) & \leqslant \max \left\{\frac{k}{b} d\left(S x_{n}, T u\right), \frac{k}{b} d\left(f x_{n}, S x_{n}\right), \frac{k}{1-k} d\left(f x_{n}, T u\right), \frac{k}{b} d\left(f x_{n}, T u\right), \frac{k}{1-k} d\left(S x_{n}, f x_{n}\right)\right\} \\
& \leqslant \frac{k}{1-k} \max \left\{d\left(S x_{n}, T u\right), d\left(f x_{n}, S x_{n}\right), d\left(f x_{n}, T u\right)\right\} \\
& \leqslant \frac{b k}{1-k}\left[d\left(S x_{n}, T u\right)+d\left(f x_{n}, T u\right)\right] .
\end{aligned}
$$

Using (2.2), we have $d\left(f x_{n}, g u\right) \rightarrow 0$ as $n \rightarrow \infty$. By Remark 1.3, we get $g u=T u$.

Step 2. We prove that $f v=S v$, that is $(f, S)$ has a point of coincidence in $X$. From (2.1), we see that

$$
d\left(f v, g y_{n}\right) \leqslant \frac{k}{b} \max \left\{d\left(S v, T y_{n}\right), d(f v, S v), d\left(g y_{n}, T y_{n}\right), d\left(f v, T y_{n}\right), d\left(S v, g y_{n}\right)\right\}
$$

Notice the following two facts.

(i) $d\left(f v, g y_{n}\right) \leqslant \frac{k}{b} d(f v, S v) \leqslant k d\left(f v, g y_{n}\right)+k d\left(g y_{n}, S v\right)$ implies $d\left(f v, g y_{n}\right) \leqslant \frac{k}{1-k} d\left(g y_{n}, S v\right)$.

(ii) $d\left(f v, g y_{n}\right) \leqslant \frac{k}{b} d\left(f v, T y_{n}\right) \leqslant k d\left(f v, g y_{n}\right)+k d\left(g y_{n}, T y_{n}\right)$ implies $d\left(f v, g y_{n}\right) \leqslant \frac{k}{1-k} d\left(g y_{n}, T y_{n}\right)$.

Thus, using (2.5) and $\frac{k}{b}<\frac{k}{1-k}$, we deduce that

$$
\begin{aligned}
d\left(f v, g y_{n}\right) & \leqslant \max \left\{\frac{k}{b} d\left(S v, T y_{n}\right), \frac{k}{1-k} d\left(g y_{n}, S v\right), \frac{k}{b} d\left(g y_{n}, T y_{n}\right), \frac{k}{1-k} d\left(g y_{n}, T y_{n}\right), \frac{k}{b} d\left(S v, g y_{n}\right)\right\} \\
& \leqslant \frac{k}{1-k} \max \left\{d\left(S v, T y_{n}\right), d\left(g y_{n}, S v\right), d\left(g y_{n}, T y_{n}\right)\right\} \\
& \leqslant \frac{b k}{1-k}\left[d\left(g y_{n}, S v\right)+d\left(S v, T y_{n}\right)\right] .
\end{aligned}
$$

Using (2.3), we have $d\left(f v, g y_{n}\right) \rightarrow 0$ as $n \rightarrow \infty$. By Remark 1.3, we get $f v=S v$.

Step 3. Assume that the pairs $(f, S)$ and $(g, T)$ are weakly compatible. Then we prove $f, g, S$, and $T$ have a unique common fixed point. Let $q=T u=g u$ and $p=S v=f v$. Then we claim that $p=q$. In fact, using (2.1), we have

$$
\begin{aligned}
d(p, q)=d(f v, g u) & \leqslant \frac{k}{b} \max \{d(S v, T u), d(f v, S v), d(g u, T u), d(f v, T u), d(S v, g u)\} \\
& =\frac{k}{b} \max \{d(p, q), d(p, p), d(q, q), d(p, q), d(p, q)\} \\
& =\frac{k}{b} d(p, q) .
\end{aligned}
$$

By $\frac{k}{b}<1$, we get $p=q$. Since the pairs $(f, S)$ and $(g, T)$ are weakly compatible, we have that

$$
\mathrm{fp}=\mathrm{fS} v=\mathrm{Sf} v=\mathrm{Sp} \text { and } g \mathrm{q}=\mathrm{gTu}=\mathrm{Tgu}=\mathrm{Tq} .
$$

Now, we prove $f q=q$. Using (2.1), we have

$$
\begin{aligned}
d(f p, q)=d(f p, g u) & \leqslant \frac{k}{b} \max \{d(S p, T u), d(f p, S p), d(g u, T u), d(f p, T u), d(S p, g u)\} \\
& =\frac{k}{b} \max \{d(f p, q), 0,0, d(f p, q), d(f p, q)\}=\frac{k}{b} d(f p, q) .
\end{aligned}
$$


By $\frac{k}{b}<1$, we get $f p=q$. Similarly, we have $p=g q$. Using $p=q, f p=S p$, and $g q=T q$, it follows that $S p=f p=T p=g p=p$, that is, $p$ is a common fixed point of $f, g, S$, and $T$.

Finally, we show that the common fixed point of $f, g, S$, and $T$ is unique. Actually, suppose that $r$ is also a common fixed point of $f, g, S$, and $T$. Then, by (2.1), we derive that

$$
d(p, r)=d(f p, g r) \leqslant \frac{k}{b} \max \{d(S p, T r), d(f p, S p), d(g r, T r), d(f p, T r), d(S p, g r)\}=\frac{k}{b} d(p, r) .
$$

From $\frac{k}{b}<1$, it follows that $p=r$ and the uniqueness is proved.

If the b-metric $d$ is continuous, then the contractive constant $\frac{k}{b}$ in Theorem 2.1 can be enlarged to $k$.

Theorem 2.2. Let $(X, d)$ be a b-metric space with $\mathrm{s} \geqslant 1$, where $\mathrm{d}$ is continuous, and $\mathrm{f}, \mathrm{g}, \mathrm{S}, \mathrm{T}: \mathrm{X} \rightarrow \mathrm{X}$ four self-mappings. Suppose that there exists $\mathrm{k} \in[0,1)$ such that

$$
d(f x, g y) \leqslant k \max \{d(S x, T y), d(f x, S x), d(g y, T y), d(f x, T y), d(S x, g y)\}
$$

for all $x, y \in X$. If $(f, S)$ satisfies the (CLRT)-property and $(\mathrm{g}, \mathrm{T})$ satisfies the (CLRS)-property, then $(\mathrm{f}, \mathrm{S})$ and $(g, T)$ have a point of coincidence in X. Moreover, if the pairs $(f, S)$ and $(g, T)$ are weakly compatible, then $f, g, S$, and $\mathrm{T}$ have a unique common fixed point.

Proof. As $(f, S)$ satisfies the (CLRT)-property and $(g, T)$ satisfies the (CLRS)-property, there exist sequences $\left\{x_{n}\right\}$ and $\left\{y_{n}\right\}$ in $X$ and $u, v \in X$ such that

$$
\lim _{n \rightarrow \infty} f x_{n}=\lim _{n \rightarrow \infty} S x_{n}=T u \in T X, \quad \lim _{n \rightarrow \infty} g y_{n}=\lim _{n \rightarrow \infty} T y_{n}=S v \in S X
$$

We prove that $T u=g u$ and $S v=f v$. Using (2.6), we see that

$$
d\left(f x_{n}, g u\right) \leqslant k \max \left\{d\left(S x_{n}, T u\right), d\left(f x_{n}, S x_{n}\right), d(g u, T u), d\left(f x_{n}, T u\right), d\left(S x_{n}, g u\right)\right\} .
$$

Letting $n \rightarrow \infty$ in both sides of the above inequality, using the continuity of $d$, we have that

$$
d(T u, g u) \leqslant k \max \{d(T u, T u), d(T u, T u), d(g u, T u), d(T u, T u), d(T u, g u)\}=k d(T u, g u) .
$$

From $k<1$, we see that $d(T u, g u)=0$ and $g u=T u$. Similarly, we can show that $f v=S v$.

The remainder of the proof is similar to Step 3 of the proof in Theorem 2.1.

Theorem 2.3. Let $(X, d)$ be a b-metric space with $\mathrm{s} \geqslant 1$ and $\mathrm{f}, \mathrm{g}, \mathrm{S}, \mathrm{T}: \mathrm{X} \rightarrow \mathrm{X}$ four self-mappings. Suppose that all hypotheses of Theorem 2.1 hold. Let $p \in X$ be the common fixed point of $\mathrm{f}, \mathrm{g}, \mathrm{S}$, and $\mathrm{T}$. Then the following statements hold.

(i) If $(f, S)$ is a pair of R-weakly commuting mappings of type $\left(A_{S}\right)$ and $f$ or $S$ is b-continuous at $p$, then

$$
\lim _{n \rightarrow \infty} d\left(f S x_{n}, S f x_{n}\right)=0,
$$

where the sequence $\left\{x_{n}\right\}$ is given in (2.2).

(ii) If $(\mathrm{g}, \mathrm{T})$ is a pair of $\mathrm{R}$-weakly commuting mappings of type $\left(\mathrm{A}_{\mathrm{T}}\right)$ and $\mathrm{g}$ or $\mathrm{T}$ is b-continuous at $\mathrm{p}$, then

$$
\lim _{n \rightarrow \infty} d\left(g T y_{n}, T g y_{n}\right)=0,
$$

where the sequence $\left\{y_{n}\right\}$ is given in (2.3).

Proof. We only prove (i). For this, we consider the following two cases. 
(1) If $\mathrm{f}$ is b-continuous at $p$, from $f x_{n} \rightarrow T u=p$ and $S x_{n} \rightarrow T u=p$, it follows that

$$
f f x_{n} \rightarrow f p=p \text { and } f S x_{n} \rightarrow f p=p .
$$

Since $f$ and $S$ are R-weakly commuting mappings of type $\left(A_{S}\right)$, we have that

$$
\begin{aligned}
d\left(S f x_{n}, f S x_{n}\right) & \leqslant b d\left(S f x_{n}, f f x_{n}\right)+b^{2} d\left(f f x_{n}, p\right)+b^{2} d\left(p, f S x_{n}\right) \\
& \leqslant b R d\left(S x_{n}, f x_{n}\right)+b^{2} d\left(f f x_{n}, z\right)+b^{2} d\left(z, f g x_{n}\right),
\end{aligned}
$$

which implies that $d\left(S f x_{n}, f S x_{n}\right) \rightarrow 0$ as $n \rightarrow \infty$.

(2) If $S$ is b-continuous at $p$, from $f x_{n} \rightarrow T u=p$ and $S x_{n} \rightarrow T u=p$, it follows that

$$
\lim _{n \rightarrow \infty} S f x_{n}=S p=p=g u \text { and } \lim _{n \rightarrow \infty} S S x_{n}=S p=p=g u \text {. }
$$

We claim that $d\left(f S x_{n}, p\right) \rightarrow 0$. Using this claim, $d\left(f S x_{n}, S f x_{n}\right) \leqslant b d\left(f S x_{n}, p\right)+b d\left(p, S f x_{n}\right)$ and $d\left(p, S f x_{n}\right) \rightarrow$ 0 , we obtain

$$
\lim _{n \rightarrow \infty} d\left(f S x_{n}, S f x_{n}\right)=0 .
$$

Now, we prove our claim. Using (2.1), we have that

$$
\begin{aligned}
d\left(f S x_{n}, p\right)=d\left(f S x_{n}, g u\right) & \leqslant \frac{k}{b} \max \left\{d\left(S S x_{n}, T u\right), d\left(f S x_{n}, S S x_{n}\right), d(g u, T u), d\left(f S x_{n}, T u\right), d\left(S S x_{n}, g u\right)\right\} \\
& =\frac{k}{b} \max \left\{d\left(S S x_{n}, p\right), d\left(f S x_{n}, S S x_{n}\right), d\left(f S x_{n}, p\right)\right\} .
\end{aligned}
$$

From this, we get the following cases.

Case i. If $\max \left\{d\left(S S x_{n}, p\right), d\left(f S x_{n}, S S x_{n}\right), d\left(f S x_{n}, p\right)\right\}=d\left(S S x_{n}, p\right)$, then $d\left(f g x_{n}, p\right) \leqslant \frac{k}{b} d\left(S S x_{n}, p\right)$.

Case ii. If $\max \left\{d\left(S S x_{n}, p\right), d\left(f S x_{n}, S S x_{n}\right), d\left(f S x_{n}, p\right)\right\}=d\left(f S x_{n}, S S x_{n}\right)$, then

$$
d\left(f S x_{n}, p\right) \leqslant \frac{k}{b} d\left(f S x_{n}, S S x_{n}\right) \leqslant k d\left(f S x_{n}, p\right)+k d\left(p, S S x_{n}\right) .
$$

This implies that

$$
d\left(f S x_{n}, p\right) \leqslant \frac{k}{1-k} d\left(p, S S x_{n}\right) .
$$

Case iii. If $\max \left\{d\left(S S x_{n}, p\right), d\left(f S x_{n}, S S x_{n}\right), d\left(f S x_{n}, p\right)\right\}=d\left(f S x_{n}, p\right)$, then $d\left(f S x_{n}, p\right) \leqslant \frac{k}{b} d\left(f S x_{n}, p\right)$. By $\frac{k}{b}<1$, we have $d\left(f S x_{n}, p\right)=0$.

In conclusion,

$$
d\left(f S x_{n}, p\right) \leqslant \max \left\{\frac{k}{b} d\left(S S x_{n}, p\right), \frac{k}{1-k} d\left(p, S S x_{n}\right)\right\}=\frac{k}{1-k} d\left(p, S S x_{n}\right) \rightarrow 0 .
$$

This implies that $d\left(f S x_{n}, p\right) \rightarrow 0$. The proof has been completed.

If we take $f=g$ and $S=T$ in Theorem 2.1 and Theorem 2.3, by Remark 1.7, we get the following.

Corollary 2.4. Let $(\mathrm{X}, \mathrm{d})$ be a b-metric space and let $\mathrm{f}, \mathrm{S}: \mathrm{X} \rightarrow \mathrm{X}$ be two self-mappings satisfying the (CLRS)property. Suppose that there exists $\mathrm{k} \in[0,1)$ such that

$$
d(f x, f y) \leqslant \frac{k}{b} \max \{d(S x, S y), d(f x, S x), d(f y, S y), d(f x, S y), d(S x, f y)\}
$$

for all $x, y \in X$. If $(f, S)$ is a pair of R-weakly commuting mappings of type $\left(A_{S}\right)$, then $f$ and $S$ have a unique common fixed point (say $z$ ). And if we additionally assume that $\mathrm{f}$ or $\mathrm{S}$ is b-continuous at $z$, then

$$
\lim _{n \rightarrow \infty} d\left(S f x_{n}, f S x_{n}\right)=0,
$$

where the sequence $\left\{x_{n}\right\}$ is given in (1.1). 
Remark 2.5.

(1) From Lemmas 1.12 and 1.13, we see that Theorem 1.9 (that is, [24, Theorem 2.1]) is the special case of Corollary 2.4.

(2) In [24, Theorem 2.1], the authors assumed that $f$ and $g$ are not compatible, and it is announced that $f$ and $S$ are not continuous at $z$, where $z$ is the common fixed point of $f$ and $S$. However, the argument given by the authors to prove that $S$ is not b-continuous at $z$ is not correct. assuming that $S$ is continuous at $z$, it is proved that $\left\{S f x_{n}\right\}$ converges to $f z$, where $f x_{n} \rightarrow z$, but this does not contradict with $S$ being not b-continuous at $z$; also see [21, Remark 11]. By Corollary 2.4, if we assume that $f$ and $S$ are not compatible and $\overline{f X} \subseteq S X$, then $f$ and $S$ cannot be b-continuous at $z$. This means we fill this gap in [24]. lemmas.

Now, by using Theorem 2.1, we deduce the main results in [19]. To the end, we need the following

Lemma 2.6. Let $(\mathrm{X}, \mathrm{d})$ be a b-metric space with $\mathrm{s} \geqslant 1$ and $\mathrm{f}, \mathrm{g}, \mathrm{S}, \mathrm{T}: \mathrm{X} \rightarrow \mathrm{X}$ four self-mappings. Then the following statements hold.

(i) If $\mathrm{fX} \subseteq \mathrm{TX}$ and $\mathrm{fX}$ or $\mathrm{TX}$ is closed subset of $\mathrm{X}$, then $\overline{\mathrm{fX}} \subseteq \mathrm{TX}$.

(ii) If $\mathrm{gX} \subseteq \mathrm{SX}$ and $\mathrm{gX}$ or $\mathrm{SX}$ is closed subset of $\mathrm{X}$, then $\overline{\mathrm{gX}} \subseteq \mathrm{SX}$.

Lemma 2.7. Let $(X, d)$ be a b-metric space with $s \geqslant 1$ and let $f, g, S, T: X \rightarrow X$ be four self-mappings with $\mathrm{fX} \subseteq \mathrm{TX}$ and $\mathrm{gX} \subseteq \mathrm{SX}$ satisfying the condition (2.1). If $\overline{\mathrm{fX}} \subseteq \mathrm{TX}$ or $\overline{\mathrm{gX}} \subseteq \mathrm{SX}$, then the following statements are equivalent.

(i) $(\mathrm{f}, \mathrm{S})$ satisfies the (CLRT) property.

(ii) $(\mathrm{g}, \mathrm{T})$ satisfies the (CLRS) property.

Proof. We prove that (i) implies (ii). To this end, let ( $f, S)$ satisfy the (CLRT) property. Then there exists a sequence $\left\{x_{n}\right\}$ in $X$ such that

$$
\lim _{n \rightarrow \infty} f x_{n}=\lim _{n \rightarrow \infty} S x_{n}=T u \in T X
$$

for some $u \in X$. As $f X \subseteq T X$, there exists a sequence $\left\{y_{n}\right\}$ in $X$ such that $f x_{n}=T y_{n}$. Let us prove $\lim _{n \rightarrow \infty} g y_{n}=T u$. Using (2.1), we have

$$
\begin{aligned}
d\left(f x_{n}, g y_{n}\right) & \leqslant \frac{k}{b} \max \left\{d\left(S x_{n}, T y_{n}\right), d\left(f x_{n}, S x_{n}\right), d\left(g y_{n}, T y_{n}\right), d\left(f x_{n}, T y_{n}\right), d\left(S x_{n}, g y_{n}\right)\right\} \\
& =\frac{k}{b} \max \left\{d\left(S x_{n}, f x_{n}\right), d\left(g y_{n}, f x_{n}\right), d\left(S x_{n}, g y_{n}\right)\right\} .
\end{aligned}
$$

From this, we get the following cases.

Case i. If $\max \left\{d\left(S x_{n}, f x_{n}\right), d\left(g y_{n}, f x_{n}\right), d\left(S x_{n}, g y_{n}\right)\right\}=d\left(S x_{n}, f x_{n}\right)$, then $d\left(f x_{n}, g y_{n}\right) \leqslant \frac{k}{b} d\left(S x_{n}, f x_{n}\right)$.

Case ii. If $\max \left\{d\left(S x_{n}, f x_{n}\right), d\left(g y_{n}, f x_{n}\right), d\left(S x_{n}, g y_{n}\right)\right\}=d\left(g y_{n}, f x_{n}\right)$, then $d\left(f x_{n}, g y_{n}\right) \leqslant \frac{k}{b} d\left(g y_{n}, f x_{n}\right)$. By $\frac{k}{b}<1$, we get $d\left(f x_{n}, g y_{n}\right)=0$.

Case iii. If $\max \left\{d\left(S x_{n}, f x_{n}\right), d\left(g y_{n}, f x_{n}\right), d\left(S x_{n}, g y_{n}\right)\right\}=d\left(S x_{n}, g y_{n}\right)$, then $d\left(f x_{n}, g y_{n}\right) \leqslant \frac{k}{b} d\left(S x_{n}, g y_{n}\right) \leqslant$ $k d\left(S x_{n}, f x_{n}\right)+k d\left(f x_{n}, g y_{n}\right)$, which implies $d\left(f x_{n}, g y_{n}\right) \leqslant \frac{k}{1-k} d\left(S x_{n}, f x_{n}\right)$. Thus we obtain $d\left(f x_{n}, g y_{n}\right) \leqslant$ $\max \left\{\frac{k}{b} d\left(S x_{n}, f x_{n}\right), \frac{k}{1-k} d\left(S x_{n}, f x_{n}\right)\right\}=\frac{k}{1-k} d\left(S x_{n}, f x_{n}\right)$. From $d\left(S x_{n}, f x_{n}\right) \leqslant b d\left(S x_{n}, T u\right)+b d\left(T u, f x_{n}\right)$, it follows that $d\left(S x_{n}, f x_{n}\right) \rightarrow 0$ and $d\left(f x_{n}, g y_{n}\right) \rightarrow 0$. Using $d\left(g y_{n}, T u\right) \leqslant b d\left(g y_{n}, f x_{n}\right)+b d\left(f_{n}, T u\right)$, we see that $\lim _{n \rightarrow \infty} g y_{n}=T u$.

If $\overline{\mathrm{gX}} \subseteq \mathrm{SX}$, there exists $v \in X$ such that $\mathrm{Tu}=S v$. Therefore we get

$$
\lim _{n \rightarrow \infty} T y_{n}=\lim _{n \rightarrow \infty} g y_{n}=T u=S v
$$

that is $(g, T)$ satisfies the (CLRS) property. 
If $\overline{f X} \subseteq T X$, we prove that $(g, T)$ satisfies the (CLRS) property. We claim that $g u=T u$. By $g X \subseteq S X$, there exists $v \in X$ such that $g u=S v$. Therefore we get

$$
\lim _{n \rightarrow \infty} T y_{n}=\lim _{n \rightarrow \infty} g y_{n}=T u=g u=S v,
$$

that is $(\mathrm{g}, \mathrm{T})$ satisfies the (CLRS) property.

Now we prove our claim. From (2.1), we see that

$$
d\left(f x_{n}, g u\right) \leqslant \frac{k}{b} \max \left\{d\left(S x_{n}, T u\right), d\left(f x_{n}, S x_{n}\right), d(T u, g u), d\left(f x_{n}, T u\right), d\left(S x_{n}, g u\right)\right\} .
$$

Notice the following two facts.

(i) $d\left(f x_{n}, g u\right) \leqslant \frac{k}{b} d(T u, g u) \leqslant k d\left(T u, f x_{n}\right)+k d\left(f x_{n}, g u\right)$ implies $d\left(f x_{n}, g u\right) \leqslant \frac{k}{1-k} d\left(T u, f x_{n}\right)$.

(ii) $d\left(f x_{n}, g u\right) \leqslant \frac{k}{b} d\left(S x_{n}, g u\right) \leqslant k d\left(S x_{n}, f x_{n}\right)+k d\left(f x_{n}, g u\right)$ implies $d\left(f x_{n}, g u\right) \leqslant \frac{k}{1-k} d\left(S x_{n}, f x_{n}\right)$.

Thus, by $\frac{k}{b}<\frac{k}{1-k}$, we deduce that

$$
\begin{aligned}
d\left(f x_{n}, g u\right) & \leqslant \max \left\{\frac{k}{b} d\left(S x_{n}, T u\right), \frac{k}{b} d\left(f x_{n}, S x_{n}\right), \frac{k}{1-k} d\left(T u, f x_{n}\right), \frac{k}{b} d\left(f x_{n}, T u\right), \frac{k}{1-k} d\left(S x_{n}, f x_{n}\right)\right\} \\
& \leqslant \frac{k}{1-k} \max \left\{d\left(S x_{n}, T u\right), d\left(f x_{n}, S x_{n}\right), d\left(T u, f x_{n}\right)\right\} \\
& \leqslant \frac{b k}{1-k}\left[d\left(f x_{n}, T u\right)+d\left(T u, S x_{n}\right)\right] .
\end{aligned}
$$

Since $d\left(f x_{n}, T u\right) \rightarrow 0$ and $d\left(T u, S x_{n}\right) \rightarrow 0$, we have that $d\left(f x_{n}, g u\right) \rightarrow 0$ as $n \rightarrow \infty$. By Remark 1.3, we get $g u=T u$.

The proof that (ii) implies (i), follows by a similar argument as one of (i) implies (ii).

Let $f, g, S, T: X \rightarrow X$ be four self-mappings with $f X \subseteq T X$ and $g X \subseteq S X$ satisfying the condition (2.1). By Lemmas 1.13, 2.6, and 2.7, we see that if one of the subsets $f X, g X, S X$, and TX is closed in $X$ and one of the pairs $(f, S)$ and $(g, T)$ satisfies the b-(E.A)-property, then $(f, S)$ satisfies the (CLRT)-property and $(g, T)$ satisfies the (CLRS)-property. Thus, by Theorem 2.1, we have the following results.

Corollary 2.8 ([19, Theorem 16]). Let (X, d) be a b-metric space with $\mathrm{s} \geqslant 1$ and let $\mathrm{f}, \mathrm{g}, \mathrm{S}, \mathrm{T}: \mathrm{X} \rightarrow \mathrm{X}$ be four self-mappings with $\mathrm{fX} \subseteq \mathrm{TX}$ and $\mathrm{gX} \subseteq \mathrm{SX}$ satisfying the condition (2.1). Suppose that one of the pairs $(f, S)$ and $(\mathrm{g}, \mathrm{T})$ satisfies the $\mathrm{b}-(\mathrm{E} . \mathrm{A})$-property and that one of the subsets $\mathrm{fX}, \mathrm{gX}, \mathrm{SX}$, and $\mathrm{TX}$ is closed in $\mathrm{X}$. Then $(\mathrm{f}, \mathrm{S})$ and $(\mathrm{g}, \mathrm{T})$ have a point of coincidence in X. Moreover, if the pairs $(\mathrm{f}, \mathrm{S})$ and $(\mathrm{g}, \mathrm{T})$ are weakly compatible, then $\mathrm{f}, \mathrm{g}, \mathrm{S}$, and $\mathrm{T}$ have a unique common fixed point.

Corollary 2.9. Let $(\mathrm{X}, \mathrm{d})$ be a b-metric space with $\mathrm{s} \geqslant 1$ and let $\mathrm{f}, \mathrm{g}, \mathrm{S}, \mathrm{T}: \mathrm{X} \rightarrow \mathrm{X}$ be four self-mappings with $\overline{\mathrm{fX}} \subseteq \mathrm{TX}$ and $\overline{\mathrm{gX}} \subseteq \mathrm{SX}$ satisfying the condition (2.1). Suppose that one of the conditions $(\mathrm{f}, \mathrm{S})$ satisfying the (CLRT)-property and $(\mathrm{g}, \mathrm{T})$ satisfying the (CLRS)-property holds. Then $(\mathrm{f}, \mathrm{S})$ and $(\mathrm{g}, \mathrm{T})$ have a point of coincidence in X. Moreover, if the pairs $(\mathrm{f}, \mathrm{S})$ and $(\mathrm{g}, \mathrm{T})$ are weakly compatible, then $\mathrm{f}, \mathrm{g}, \mathrm{S}$, and $\mathrm{T}$ have a unique common fixed point.

Remark 2.10. We see that [19, Theorem 10] and [19, Theorem 15] are the special cases of Corollary 2.8.

The next is an example where we can apply Theorems 2.1 and 2.2 but not Theorem 1.9 or Corollary 2.8.

Example 2.11. Let $X=[1,10)$ and let $d: X \times X \rightarrow[0, \infty)$ be defined by $d(x, y)=(x-y)^{2}$. We define mappings $f, g, S$, and $T$ on $X$ by

$$
f x=g x= \begin{cases}1, & x=1 \text { or } x \in(5,10) \\ 6, & x \in(1,5]\end{cases}
$$


and

$$
S x=T x= \begin{cases}1, & x=1 \\ 9, & x \in(1,5] \\ \frac{x+1}{6}, & x \in(5,10) .\end{cases}
$$

Obviously, $d$ is a b-metric with $b=2$ and $\overline{f X}=f X=\overline{g X}=g X \nsubseteq S X=T X$. To prove that $(f, S)$ satisfies the $(C L R T)$-property and $(g, T)$ satisfies the (CLRS)-property, consider a sequence $\left\{x_{n}\right\}$ defined by $x_{n}=5+\frac{1}{n}$. We have

$$
\lim _{n \rightarrow \infty} f x_{n}=\lim _{n \rightarrow \infty} S x_{n}=1=T 1 \in T X \text { and } \lim _{n \rightarrow \infty} g x_{n}=\lim _{n \rightarrow \infty} T x_{n}=1=S 1 \in S X .
$$

On the other hand,

$$
d(g f x, f f x)= \begin{cases}(1-1)^{2}=0, & x=1 \\ \left(\frac{7}{6}-1\right)^{2}=\frac{1}{36}, & x \in(1,5] \\ (1-1)^{2}=0, & x \in(5,10)\end{cases}
$$

and

$$
d(f x, g x)= \begin{cases}(1-1)^{2}=0, & x=1 \\ (6-9)^{2}=9, & x \in(1,5] \\ \left(\frac{x+1}{6}-1\right)^{2}, & x \in(5,10)\end{cases}
$$

for all $x \in X$, and hence there exists $R=1$ such that

$$
d(g f x, f f x) \leqslant d(f x, g x) .
$$

That is, $(f, S)$ is R-weakly commuting mappings of type $\left(A_{S}\right)$ and $(g, T)$ is R-weakly commuting mapping of type $\left(A_{T}\right)$. By Remark 1.7, we get that $(f, S)$ and $(g, T)$ are weakly compatible. Now we prove that the mappings $f, g, S$, and $T$ satisfy the condition (2.1) of Theorem 2.1 with $k=\frac{13}{16}$. For this, we consider the following cases:

(1) If $x, y \in\{1\} \cup(5,10)$, then we have

$$
d(f x, g y)=d(1,1)=0 \leqslant \frac{k}{b} \max \{d(S x, T y), d(f x, S x), d(g y, T y), d(f x, T y), d(S x, g y)\}
$$

(2) If $x, y \in(1,5]$, then we have

$$
d(f x, g y)=d(6,6)=0 \leqslant \frac{k}{b} \max \{d(S x, T y), d(f x, S x), d(g y, T y), d(f x, T y), d(S x, g y)\}
$$

(3) If $x \in\{1\} \cup(5,10)$ and $y \in(1,5]$, then we have

$$
\begin{aligned}
& d(f x, g y)=d(1,6)=25, \\
& d(S x, T y)= \begin{cases}(1-9)^{2}=64, & x=1, \\
\left(\frac{x+1}{6}-9\right)^{2}, & x \in(5,10),\end{cases} \\
& d(f x, S x)= \begin{cases}(1-1)^{2}=0, & x=1, \\
\left(\frac{x+1}{6}-1\right)^{2}, & x \in(5,10),\end{cases} \\
& d(g y, T y)=d(6,9)=(6-9)^{2}=9, \\
& d(f x, T y)=d(1,9)=(9-1)^{2}=64,
\end{aligned}
$$

and

$$
d(S x, g y)= \begin{cases}(6-1)^{2}=16, & x=1 \\ \left(6-\frac{x+1}{6}\right)^{2}, & x \in(5,10)\end{cases}
$$


Therefore we obtain

$$
d(f x, g y) \leqslant \frac{1}{2} \cdot \frac{13}{16} \max \{d(S x, T y), d(f x, S x), d(g y, T y), d(f x, T y), d(S x, g y)\}
$$

for all $x, y \in X$. Thus all conditions of Theorem 2.1 (of course Theorem 2.2) are satisfied. In fact, 1 is a unique point in $X$ such that $f 1=g 1=1$. However, we can not apply Theorem 1.9 (i.e., [24, Theorem 2.1]) for $f$ and $S$ because $f X \nsubseteq S X$ and

$$
d(f 1, f 5)=25>\frac{1}{4} \cdot 64=\frac{1}{b^{2}} \max \{d(S 1, S 5), d(f 1, S 1), d(S 5, f 5)\} .
$$

Also, we can not apply Corollary 2.8 because $\mathrm{fX} \nsubseteq \mathrm{TX}$ and $\mathrm{gX} \nsubseteq \mathrm{SX}$.

The following two examples show that Theorems 2.1 and 2.2 are independent of each other.

Example 2.12. Let $X$ and $d$ be defined as in Example 2.11. Then $d$ is continuous. Define mappings $f, g, S$, and $\mathrm{T}$ on $\mathrm{X}$ by

$$
f x=g x= \begin{cases}1, & x=1 \text { or } x \in(5,10) \\ 6, & x \in(1,5]\end{cases}
$$

and

$$
S x=T x= \begin{cases}1, & x=1 \\ 7, & x \in(1,5] \\ \frac{x+1}{6}, & x \in(5,10)\end{cases}
$$

By the similar arguments as in Example 2.11, it can be checked that all conditions of Theorem 2.2 are satisfied. However, we can not apply Theorem 2.1 because

$$
d(f 1, g 5)=25>\frac{1}{2} \cdot 36=\frac{1}{b} \max \{d(S 1, T 5), d(f 1, S 1), d(g 5, T 5), d(f 1, T 5), d(S 1, g 5)\} .
$$

Example 2.13. Let $X=\mathbb{N} \cup\{\infty\}$ and let $d: X \times X \rightarrow[0, \infty)$ be defined by

$$
d(m, n)= \begin{cases}0, & \text { if } m=n, \\ \frac{1}{m}, & \text { if } m \text { is even and } n=\infty, \\ \frac{1}{n}, & \text { if } n \text { is even and } m=\infty, \\ \left|\frac{1}{m}-\frac{1}{n}\right|, & \text { if } m \text { and } n \text { are both even, } \\ 5, & \text { if one of } m, n \text { is odd and the other is odd (and } m \neq n \text { ) or } \infty, \\ 2, & \text { otherwise. }\end{cases}
$$

By [16, Theorem 1.5], we know that $(X, d)$ is a b-metric space with $b=\frac{5}{2}$ and $d$ is not continuous. Define mappings $f, g, S$, and $T$ on $X$ by

and

$$
f n=g n= \begin{cases}4 n, & \text { if } n \in \mathbb{N} \\ \infty, & \text { if } n=\infty\end{cases}
$$

$$
\mathrm{Sn}=\mathrm{Tn}=\mathrm{n} \text { for all } \mathrm{n} \in \mathrm{X} \text {. }
$$

Obviously, we have that $\overline{f X}=f X=\overline{g X}=g X \nsubseteq S X=T X=X$ and $(f, S)$ and $(g, T)$ are weakly compatible. Now we prove that $(f, S)$ satisfies the (CLRT)-property or $(g, T)$ satisfies the (CLRS)-property. To this end, consider a sequence $\left\{x_{n}\right\}$ defined by $x_{n}=n$. We have

$$
\lim _{n \rightarrow \infty} f x_{n}=\lim _{n \rightarrow \infty} S x_{n}=\infty=T \infty \in T X \text { and } \lim _{n \rightarrow \infty} g x_{n}=\lim _{n \rightarrow \infty} T x_{n}=\infty=S \infty \in S X .
$$

It is easy to check that mappings $f, g, S$, and T satisfy the condition (2.1) of Theorem 2.1 with $k=\frac{5}{6}$. Thus all conditions of Theorem 2.1 are satisfied. In fact, $\infty$ is a unique point in $X$ such that $f \infty=g \infty=S \infty=$ $\mathrm{T} \infty=\infty$. However, we can not apply Theorem 2.2 because $\mathrm{d}$ is not continuous. 


\section{Acknowledgment}

The authors are thankful to the referees and the editor for their valuable comments and suggestions to improve this paper. The second authors are supported by the National Natural Science Foundation of China $(11561049,11471236)$. The first and third authors are supported by the National Undergraduate Training Programs for Innovation (201510126025).

\section{References}

[1] M. Aamri, D. El Moutawakil, Some new common fixed point theorems under strict contractive conditions, J. Math. Anal. Appl., 270 (2002), 181-188. 1

[2] J. Ali, M. Imdad, D. Bahuguna, Common fixed point theorems in Menger spaces with common property (E.A), Comput. Math. Appl., 60 (2010), 3152-3159. 1

[3] H. Aydi, S. Chauhan, S. Radenović, Fixed points of weakly compatible mappings in G-metric spaces satisfying common limit range property, Facta Univ. Ser. Math. Inform., 28 (2013), 197-210. 1

[4] H. Aydi, E. Karapınar, B. Samet, Fixed points for generalized $(\alpha, \psi)$-contractions on generalized metric spaces, J. Inequal. Appl., 2014 (2014), 16 pages. 1

[5] H. Aydi, C. Vetro, W. Sintunavarat, P. Kumam, Coincidence and fixed points for contractions and cyclical contractions in partial metric spaces, Fixed Point Theory Appl., 2012 (2012), 18 pages. 1

[6] G. V. R. Babu, P. D. Sailaja, Common fixed points of $(\psi, \phi)$-weak quasi contractions with property (E.A.), Int. J. Math. Sci. Comput., 1 (2011), 29-37. 1

[7] I. A. Bakhtin, The contraction mapping principle in almost metric space, (Russian) Functional analysis, Ulyanovsk. Gos. Ped. Inst., Ulyanovsk, 30 (1989), 26-37. 1

[8] S. Banach, Sur les opérations dans les ensembles abstraits et leur application aux équations intégrales, Fund. Math., 3 (1922), 133-181. 1

[9] L. B. Ćirić, A generalization of Banach's contraction principle, Proc. Amer. Math. Soc., 45 (1974), 267-273. 1

[10] S. Czerwik, Contraction mappings in b-metric spaces, Acta Math. Inform. Univ. Ostraviensis, 1 (1993), 5-11. 1

[11] C. Di Bari, P. Vetro, Nonlinear quasi-contractions of Ćirić type, Fixed Point Theory, 13 (2012), 453-459. 1

[12] W.-S. Du, A note on cone metric fixed point theory and its equivalence, Nonlinear Anal., 72 (2010), $2259-2261$.

[13] F. He, X.-Y. Nan, A unified view on common fixed point theorems for Ćirić quasi-contraction maps, Fixed Point Theory Appl., 2015 (2015), 17 pages.

[14] M. Jovanović, Z. Kadelburg, S. Radenović, Common fixed point results in metric-type spaces, Fixed Point Theory Appl., 2010 (2010), 15 pages. 1

[15] G. Jungck, Compatible mappings and common fixed points, Internat. J. Math. Math. Sci., 9 (1986), 771-779. 1

[16] H. K. Nashine, Z. Kadelburg, Cyclic generalized $\varphi$-contractions in b-metric spaces and an application to integral equations, Filomat, 28 (2014), 2047-2057 2.13

[17] H. K. Nashine, B. Samet, C. Vetro, Fixed point theorems in partially ordered metric spaces and existence results for integral equations, Numer. Funct. Anal. Optim., 33 (2012), 1304-1320. 1

[18] T. Nazir, M. Abbas, Common fixed points of two pairs of mappings satisfying (E.A)-property in partial metric spaces, J. Inequal. Appl., 2014 (2014), 12 pages. 1

[19] V. Ozturk, S. Radenović, Some remarks on b-(E.A)-property in b-metric spaces, SpringerPlus, 5 (2016), 10 pages. 1, $1.10,1.12,2,2.8,2.10$

[20] V. Ozturk, D. Turkoglu, Common fixed point theorems for mappings satisfying (E.A)-property in b-metric spaces, J. Nonlinear Sci. Appl., 8 (2015), 1127-1133. 1, 1.10

[21] A. F. Roldán-López-de-Hierro, E. Karapınar, H. H. Alsulami, A short-note on 'Common fixed point theorems for noncompatible self-maps in generalized metric spaces', J. Inequal. Appl., 2015 (2015), 14 pages. 1, 1, 1, 2

[22] W. Sintunavarat, P. Kumam, Common fixed point theorems for a pair of weakly compatible mappings in fuzzy metric spaces, J. Appl. Math., 2011 (2011), 14 pages. 1

[23] Z.-Z. Yang, Common fixed point theorems for non-compatible self-maps in generalized metric spaces, J. Inequal. Appl., 2014 (2014), 12 pages. 1

[24] Z.-Z. Yang, H. Sadati, S. Sedghi, N. Shobe, Common fixed point theorems for non-compatible self-maps in b-metric spaces, J. Nonlinear Sci. Appl., 8 (2015), 1022-1031. 1, 1, 1, 1.9, 1, 2, 2.11 